\title{
ALGORITHM FOR AUTOMATIC DETERMINATION OF THE WIDTH OF A BIVALENT SYSTEM
}

\author{
Paul VASILIU \\ "Mircea cel Bătrân" Naval Academy, Constanța, Romania \\ p_vasiliu@yahoo.com
}

\begin{abstract}
A system is a set of elements that can be found in one of the following states: operating state and fault. Any system has two stable states: functioning and defect, which is why, in the theory of reliability, it is called a bivalent system. A subset of defective elements is called the system cut if all the other elements of the system are in operation and the system is defective. The width of a bivalent system is equal to the minimum number of elements the system cuts have. In this paper we present an algorithm for automatic determination of the width of a bivalent system, a Matlab script that implements the algorithm, a case study and subsequent development directions.
\end{abstract}

Keywords: algorithm, cut, width, reliability

\section{Introduction}

The plurality of all elements of the assembly of elements that reflect how the state of an $S$ system depends on the states of its components is called a structure.

In the reliability analysis, structures play an important role. In a first step, the structure of the equipment is analyzed, followed by establishing the algebraic expression of the structure function and then constructing a reliability network associated with that equipment.

Considerations regarding complex systems or equipment are based on the following assumptions:

The equipment considered can only be in one of the following states: operating state or fault condition (bivalent system). The considered equipment can be decomposed into $n$ components (elements) $e_{i}$, $i=1,2, \cdots, n$. The set of all these elements is: $E=\left\{e_{1}, e_{2}, \cdots, e_{n}\right\}$.
Each component $e_{i}, \quad i=1,2, \cdots, n$, is associated with a state variable $x_{i}$ defined

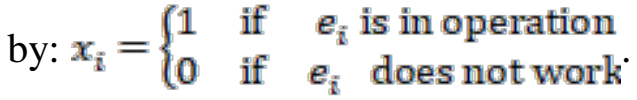

The set of states $X=\left\{x_{1}, x_{2}, \cdots, x_{n}\right\}$ characterizes the set of possible states of the assembly of elements. Obvious, $\operatorname{card}(X)=2^{n}$.

The system $S$ is associated with a state variable $y$ defined as follows:

$y=\left\{\begin{array}{ll}1 & \text { if } S \text { is in operation } \\ 0 & \text { if } S \text { does notwork }\end{array}\right.$.

Let $Y=\{y\}=\{0,1\}$. The $y$ state variable depends on the set of $X$ states.

We can define a function $\varphi: X \rightarrow Y$, defined by: $y=\varphi\left(x_{1}, x_{2}, \cdots, x_{n}\right)$. The function $\varphi$ is called the function of the structure. Since the function $\varphi$ depends on $n$ independent variables, it is called function of the $n$ order structure. The $S$ system can be identified with the pair $(E, \varphi): S=(E, \varphi)$.

Let the system $S=(E, \varphi)$. 
The subassembly $T=\left\{e_{i} \mid i \in I \subset\{1,2, \cdots, n\}\right\} \subset E$ is called a cut if for any $x_{i}=0, i \in I$ and for any $x_{i}=1, \quad i \notin I \quad$ follows: $y=\varphi\left(x_{1}, x_{2}, \cdots, x_{n}\right)=0$.

In other words, a cut of a non-functioning system $(y=0)$ is a subset (subassembly) of elements in which all elements are defective, the rest of the elements being in operation.

Reforming a cut is a subassembly of elements that are in a non-functioning state and cause the system to fail if the other elements are in operation.

Any system has at least one cut.

To determine all system cuts, calculate the values of the structure function at all points $\left(x_{1}, x_{2}, \cdots, x_{n}\right)$.

If $\quad f\left(\mathrm{x}_{1}, \mathrm{x}_{2}, \cdots, \mathrm{x}_{\mathrm{n}}\right)=0 \quad$ for $x_{i_{1}}=x_{i_{2}}=\cdots=x_{i_{p}}=0$ and $x_{i}=1$ for any $i \in\{1,2, \cdots, n\} \backslash\left\{i_{1}, i_{2}, \cdots, i_{p}\right\}$ then the subset of elements (subassembly of elements)

$\left\{e_{i_{1}}, e_{i_{2},}, \cdots, e_{i_{p}}\right\}$ is a cut.

Let $c_{k}>0$ the number of cuts with $k$ elements, $k \in N^{*}$.

It is called the width of the system $S$ number $\mu(S)=\min \left\{k \mid c_{k}>0\right\}$.

The study of the cuts and width of a system brings important information about the operation of the system under the condition that some of the component elements are defective.

The difficulty of manually determining cuts and the width of a system increases as the number of elements in the system increases. There is a need to simplify and automate the determination of system cuts and system width. For this reason, the authors wrote the Matlab functions presented in Section 2.

\section{Matlab implementation}

The Matlab main function with the signature function cuts(n) receives the $n$ value of the input. The function generates all cuts to the reliability network. The function calculates the width of the system.
The function function $w=$ conversion $(n, v)$ converts the value of the input argument $n$ from base 10 to base 2 and stores the result of the conversion in the variable $\mathrm{w}$.

The function function val=fstruct $(x)$ receives the input vector $x$ of the structure function variables and returns the value of the structure function.

The display of cuts is made by the function function write(n,w,tip).

The function function $w=i n v e r s e(v)$ inverts the vector $\mathrm{v}$ and stores the result in the vector $\mathrm{w}$.

The function function printnl(nb) displays the number of cuts with $k$ elements, $k=1,2, \cdots$

We present below the Matlab code for implementing the algorithm.

$\%$ The main function

function cuts(n)

clc;

$\mathrm{k}=2^{\wedge} \mathrm{n}$;

for $\mathrm{i}=1: \mathrm{n}$

$\mathrm{v}(\mathrm{i})=0$;

end

ival $=1$;

for $\mathrm{i}=0: \mathrm{k}-1$

$\mathrm{w}=$ conversion $(\mathrm{i}, \mathrm{v})$;

val=fstruct $(\mathrm{w})$;

if $\mathrm{val}==0$

$\operatorname{vval}($ ival) $=\mathrm{i}$;

fprintf(' The value \%d : $\ln y=f($ ',i);

$\mathrm{nb}$ (ival) $=0$;

for $j=1$ :length(w)-1

fprintf(' \%d , ',w(j));

if $w(j)==0$

$\mathrm{nb}($ ival $)=\mathrm{nb}($ ival $)+1$;

end

end

if $\mathrm{w}($ length $(\mathrm{w}))==0$

$\mathrm{nb}(\mathrm{ival})=\mathrm{nb}(\mathrm{ival})+1$;

end

fprintf(' \%d ',w(length(w)));

fprintf(' $)=\% d \backslash n ', v a l)$;

write(i,w,'t');

ival=ival +1 ;

end

end

printnt(nb); 
fprintf(' The system"s width is \%d

'n',min(nb));

end

\% Conversion function

$\%$ from base 10 in base 2

function $\mathrm{w}=$ conversion(n,v)

$\mathrm{i}=1$;

while $\mathrm{n} \sim=0$

$\mathrm{uc}=\bmod (\mathrm{n}, 2)$;

$\mathrm{v}(\mathrm{i})=\mathrm{uc}$;

$\mathrm{i}=\mathrm{i}+1$;

$\mathrm{n}=$ floor(n/2);

end

w=inverse $(v)$;

end

\% Function for reversing vector $\mathrm{v}$

function $\mathrm{w}=$ inverse $(\mathrm{v})$

$\mathrm{n}=$ length(v);

for $i=1: n$

$\mathrm{w}(\mathrm{i})=\mathrm{v}(\mathrm{n}-\mathrm{i}+1)$;

end

end

\% Function for displaying cuts

function write(n,w,tip)

$\mathrm{p}=$ length $(\mathrm{w})$;

if tip $=={ }^{\prime} \mathrm{t}$ '

fprintf(' Subassembly $\mathrm{T}=\{$ ');

for $i=1: p$

if $w(i)==0$

fprintf(' e\%d ',i);

end

end

fprintf(' $\}$ is a cut $\left.\backslash n^{\prime}\right)$;

end

end

$\%$ Function to display the number of cuts

$\%$ with $\mathrm{k}$ elements

$\% \mathrm{k}=1,2, \ldots$

function printnt(nb)

$\mathrm{kmin}=\min (\mathrm{nb})$;

$\mathrm{kmax}=\max (\mathrm{nb})$;

for $\mathrm{i}=\mathrm{kmin}: 1: \mathrm{kmax}$

$\mathrm{s}=0$;

for $\mathrm{j}=1$ :length(nb) if $n b(j)==i \& n b(j) \sim=0$

$\mathrm{s}=\mathrm{s}+1$

end

end

fprintf(' Number of \%d - element cuts $=\% d$

In',i,s);

end

end

\% Function of system structure

function val=fstruct( $(x)$

val $=1-(1-x(1) * x(2) * x(3)) *(1-x(4) * x(5))$;

end

\section{Case study}

Consider the system $S=(E, \varphi)$ with the properties:

$n=5, E=\left\{e_{1}, e_{2}, e_{3}, e_{4}, e_{5}\right\}$,

$X=\left\{x_{1}, x_{2}, x_{3}, x_{4}, x_{5}\right\}$. The graph of the system is shown in Figure 1.

Obviously, the structure function of the system is the function: $\varphi: X \rightarrow\{0,1\}$, $\varphi\left(x_{1}, x_{2}, x_{3}, x_{4}, x_{5}\right)=1-\left(1-x_{1} \times x_{2}\right.$.

$\left.x_{3}\right) \cdot\left(1-x_{4} \times x_{5}\right)$

For manual determination of all system cutss, the values of the structure function are calculated at all points $\left(x_{1}, x_{2}, x_{3}, x_{4}, x_{5}\right)$.

If for $x_{i_{1}}=x_{i_{2}}=\cdots=x_{i_{p}}=0$ and $x_{i}=1$ for any $i \in\{1,2, \cdots, n\} \backslash\left\{i_{1}, i_{2}, \cdots, i_{p}\right\}$ and $\varphi\left(x_{1}, x_{2}, \cdots, x_{n}\right)=0$ then the subassembly of elements $\left\{e_{i_{1}}, e_{i_{2}}, \cdots, e_{i_{p}}\right\}$ is a cut.

Table 1 is completed and all system cuts are obtained. 


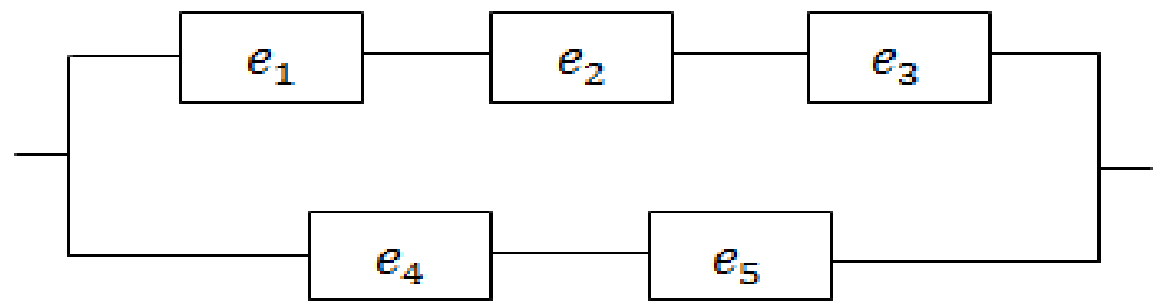

Figure 1: The system

Table 1 System links $S=(E, \varphi)$

\begin{tabular}{|c|c|c|c|c|c|c|c|}
\hline Value & $x_{1}$ & $x_{2}$ & $x_{3}$ & $x_{4}$ & $x_{5}$ & $\varphi$ & Cuts \\
\hline 0 & 0 & 0 & 0 & 0 & 0 & 0 & $\left\{e_{1}, e_{2}, e_{3}, e_{4}, e_{5}\right\}$ \\
\hline 1 & 0 & 0 & 0 & 0 & 1 & 0 & $\left\{e_{1}, e_{2}, e_{3}, e_{4}\right\}$ \\
\hline 2 & 0 & 0 & 0 & 1 & 0 & 0 & $\left\{e_{1}, e_{2}, e_{3}, e_{5}\right\}$ \\
\hline 3 & 0 & 0 & 0 & 1 & 1 & 1 & \\
\hline 4 & 0 & 0 & 1 & 0 & 0 & 0 & $\left\{e_{1}, e_{2}, e_{4}, e_{5}\right\}$ \\
\hline 5 & 0 & 0 & 1 & 0 & 1 & 0 & $\left\{e_{1}, e_{2}, e_{4}\right\}$ \\
\hline 6 & 0 & 0 & 1 & 1 & 0 & 0 & $\left\{e_{1}, e_{2}, e_{5}\right\}$ \\
\hline 7 & 0 & 0 & 1 & 1 & 1 & 1 & \\
\hline 8 & 0 & 1 & 0 & 0 & 0 & 0 & $\left\{e_{1}, e_{3}, e_{4}, e_{5}\right\}$ \\
\hline 9 & 0 & 1 & 0 & 0 & 1 & 0 & $\left\{e_{1}, e_{3}, e_{4}\right\}$ \\
\hline 10 & 0 & 1 & 0 & 1 & 0 & 0 & $\left\{e_{1}, e_{3}, e_{5}\right\}$ \\
\hline 11 & 0 & 1 & 0 & 1 & 1 & 1 & \\
\hline 12 & 0 & 1 & 1 & 0 & 0 & 0 & $\left\{e_{1}, e_{4}, e_{5}\right\}$ \\
\hline 13 & 0 & 1 & 1 & 0 & 1 & 0 & $\left\{e_{1}, e_{4}\right\}$ \\
\hline 14 & 0 & 1 & 1 & 1 & 0 & 0 & $\left\{e_{1}, e_{5}\right\}$ \\
\hline 15 & 0 & 1 & 1 & 1 & 1 & 1 & \\
\hline 16 & 1 & 0 & 0 & 0 & 0 & 0 & $\left\{e_{2}, e_{3}, e_{4}, e_{5}\right\}$ \\
\hline 17 & 1 & 0 & 0 & 0 & 1 & 0 & $\left\{e_{2}, e_{3}, e_{4}\right\}$ \\
\hline 18 & 1 & 0 & 0 & 1 & 0 & 0 & $\left\{e_{2}, e_{3}, e_{5}\right\}$ \\
\hline 19 & 1 & 0 & 0 & 1 & 1 & 1 & \\
\hline 20 & 1 & 0 & 1 & 0 & 0 & 0 & $\left\{e_{2}, e_{4}, e_{5}\right\}$ \\
\hline 21 & 1 & 0 & 1 & 0 & 1 & 0 & $\left\{e_{2}, e_{4}\right\}$ \\
\hline 22 & 1 & 0 & 1 & 1 & 0 & 0 & $\left\{e_{2}, e_{5}\right\}$ \\
\hline 23 & 1 & 0 & 1 & 1 & 1 & 1 & \\
\hline 24 & 1 & 1 & 0 & 0 & 0 & 0 & $\left\{e_{3}, e_{4}, e_{5}\right\}$ \\
\hline 25 & 1 & 1 & 0 & 0 & 1 & 0 & $\left\{e_{3}, e_{4}\right\}$ \\
\hline 26 & 1 & 1 & 0 & 1 & 0 & 0 & $\left\{e_{3}, e_{5}\right\}$ \\
\hline 27 & 1 & 1 & 0 & 1 & 1 & 1 & \\
\hline 28 & 1 & 1 & 1 & 0 & 0 & 1 & \\
\hline 29 & 1 & 1 & 1 & 0 & 1 & 1 & \\
\hline 30 & 1 & 1 & 1 & 1 & 0 & 1 & \\
\hline 31 & 1 & 1 & 1 & 1 & 1 & 1 & \\
\hline
\end{tabular}


To determine the width of the system, the numbers are determined:

$c_{2}=6$ because there are six cuts each with two elements (cuts: $\left\{e_{1}, e_{4}\right\},\left\{e_{1}, e_{5}\right\}$, $\left\{e_{2}, e_{4}\right\},\left\{e_{2}, e_{5}\right\},\left\{e_{3}, e_{4}\right\}$ and $\left.\left\{e_{3}, e_{5}\right\}\right)$;

$c_{3}=9$ because there are nine cuts each with three elements (cuts: $\left\{e_{1}, e_{2}, e_{4}\right\}$, $\left\{e_{1}, e_{2}, e_{5}\right\}, \quad\left\{e_{1}, e_{3}, e_{4}\right\}, \quad\left\{e_{1}, e_{3}, e_{5}\right\}$, $\left\{e_{1}, e_{4}, e_{5}\right\}, \quad\left\{e_{2}, e_{3}, e_{4}\right\}, \quad\left\{e_{2}, e_{3}, e_{5}\right\}$, $\left\{e_{2}, e_{4}, e_{5}\right\}$ and $\left\{e_{3}, e_{4}, e_{5}\right\}$ );

$c_{4}=5$ because there are five cuts each with four elements (cuts: $\left\{e_{1}, e_{2}, e_{3}, e_{4}\right\}$, $\left\{e_{1}, e_{2}, e_{3}, e_{5}\right\},\left\{e_{1}, e_{2}, e_{4}, e_{5}\right\},\left\{e_{1}, e_{3}, e_{4}, e_{5}\right\}$ and $\left.\left\{e_{2}, e_{3}, e_{4}, e_{5}\right\}\right)$;

$c_{5}=1$ because there is only one cut with five elements

(cut:

$\left.\left\{e_{1}, e_{2}, e_{3}, e_{4}, e_{5}\right\}\right)$.

The $S$ system width is equal to: $\mu(S)=\min \left\{k \mid c_{k}>0\right\}=\min \{2,3,4,5\}=$ 2

Using the Matlab function above, we will determine all the cuts of this system and the width of the system.

The structure function denoted by $\varphi$ coincides with the function denoted by $\boldsymbol{f}$ in the Matlab code.

An example of execution is:

$>>$ cuts(5)

The value 0 :

$\mathrm{y}=\mathrm{f}(0,0,0,0,0)=0$

Subassembly $\mathrm{T}=\{$ e1 e2 e3 e4 e5 $\}$ is a cut

The value 1 :

$\mathrm{y}=\mathrm{f}(0,0,0,0,1)=0$

Subassembly $\mathrm{T}=\{$ e1 e2 e3 e4 $\}$ is a cut The value 2 :

$y=f(0,0,0,1,0)=0$

Subassembly $\mathrm{T}=\{$ e1 e2 e3 e5 $\}$ is a cut

The value 4 :

$\mathrm{y}=\mathrm{f}(0,0,1,0,0)=0$

Subassembly $\mathrm{T}=\{$ e1 e2 e4 e5 $\}$ is a cut

The value 5 :

$\mathrm{y}=\mathrm{f}(0,0,1,0,1)=0$

Subassembly $\mathrm{T}=\{$ e1 e2 e4 $\}$ is a cut

The value 6 : $\mathrm{y}=\mathrm{f}(0,0,1,1,0)=0$

Subassembly $\mathrm{T}=\{$ e1 e2 e5 $\}$ is a cut

The value 8 :

$\mathrm{y}=\mathrm{f}(0,1,0,0,0)=0$

Subassembly $\mathrm{T}=\{$ e1 e3 e4 e5 $\}$ is a cut

The value 9 :

$\mathrm{y}=\mathrm{f}(0,1,0,0,1)=0$

Subassembly $\mathrm{T}=\{$ e1 e3 e4 $\}$ is a cut

The value 10 :

$\mathrm{y}=\mathrm{f}(0,1,0,1,0)=0$

Subassembly $\mathrm{T}=\{$ e1 e3 e5 $\}$ is a cut

The value 12 :

$\mathrm{y}=\mathrm{f}(0,1,1,0,0)=0$

Subassembly $\mathrm{T}=\{$ e1 e4 e5 $\}$ is a cut

The value 13 :

$\mathrm{y}=\mathrm{f}(0,1,1,0,1)=0$

Subassembly $\mathrm{T}=\{$ e1 e4 $\}$ is a cut

The value 14 :

$\mathrm{y}=\mathrm{f}(0,1,1,1,0)=0$

Subassembly $\mathrm{T}=\{$ e1 e5 $\}$ is a cut

The value 16 :

$\mathrm{y}=\mathrm{f}(1,0,0,0,0)=0$

Subassembly $\mathrm{T}=\{$ e2 e3 e4 e5 $\}$ is a cut

The value 17 :

$\mathrm{y}=\mathrm{f}(1,0,0,0,1)=0$

Subassembly $\mathrm{T}=\{$ e2 e3 e4 $\}$ is a cut

The value 18 :

$\mathrm{y}=\mathrm{f}(1,0,0,1,0)=0$

Subassembly $\mathrm{T}=\{$ e2 e3 e5 $\}$ is a cut

The value 20 :

$\mathrm{y}=\mathrm{f}(1,0,1,0,0)=0$

Subassembly $\mathrm{T}=\{$ e2 e4 e5 $\}$ is a cut

The value 21 :

$\mathrm{y}=\mathrm{f}(1,0,1,0,1)=0$

Subassembly $\mathrm{T}=\{$ e2 e4 $\}$ is a cut

The value 22 :

$\mathrm{y}=\mathrm{f}(1,0,1,1,0)=0$

Subassembly $\mathrm{T}=\{\mathrm{e} 2$ e5 $\}$ is a cut

The value 24 :

$\mathrm{y}=\mathrm{f}(1,1,0,0,0)=0$

Subassembly $\mathrm{T}=\{$ e3 e4 e5 $\}$ is a cut

The value 25 :

$\mathrm{y}=\mathrm{f}(1,1,0,0,1)=0$

Subassembly $\mathrm{T}=\{$ e3 e4 $\}$ is a cut

The value 26 :

$\mathrm{y}=\mathrm{f}(1,1,0,1,0)=0$ 
Subassembly $\mathrm{T}=\{$ e3 e5 $\}$ is a cut

Number of 2 - element cuts $=6$

Number of 3 - element cuts $=9$

Number of 4 - element cuts $=5$

Number of 5 - element cuts $=1$

The system's width is 2

It is easy to see that the cuts generated by the Matlab function coincide with the cuts determined manually in Table 1.

Also, the system width with the Matlab function coincides with the one determined manually.

\section{Conclusions}

Let $\quad n \in N^{*}, \quad E=\left\{e_{1}, e_{2}, \cdots, e_{n}\right\}$, $X=\left\{x_{1}, x_{2}, \cdots, x_{n}\right\}$, function $\varphi: X \rightarrow\{0,1\}$, $y=\varphi\left(x_{1}, x_{2}, \cdots, x_{n}\right), \quad$ and the system $S=(E, \varphi)$. It's called the dual system of the system $S=(E, \varphi) \quad$ the system $S^{d}=\left(E, \varphi^{d}\right)$ where the structure function $\varphi^{d}: X \rightarrow\{0,1\}$ is defined by $\varphi^{d}\left(x_{1}, x_{2}, \cdots, x_{n}\right)=1-\varphi\left(1-x_{1}, 1-\right.$ $\left.x_{2}, \cdots, 1-x_{n}\right)$

One of the developments in this article is the automatic determination of the cuts and width of the dual system of a given system. Another development is the determination of the minimal cuts of the $S=(E, \varphi)$ system and its dual $S^{d}=\left(E, \varphi^{d}\right)$ system.

\section{Acknowledgements}

The author thanks this way to all those who contributed in one way or another to the elaboration of this work.

\section{References}

[1] Cătuneanu, V.,M., Mihalache, A., Bazele teoretice ale fiabilităţii, Ed. Academiei, 1983, Bucureşti, România.

[2] Panaite, V., Popescu, M.,O., Calitatea produselor şi fiabilitate, Ed. Matrix Rom, 2003, Bucureşti, România.

[3] Ţârcolea, C., Filipoiu, A., Bontaş, S., Tehnici actuale în teoria fiabilităţii, Ed. Ştiinţifică şi Enciclopedică, 1989, Bucureşti, România.

[4] Vasiliu P., Deliu F., Funcţie Matlab pentru determinarea legăturilor unei rețele de fiabilitate, Buletinul AGIR nr. 4/2017, pag. 24-27.

[5] Vasiliu, P., Programare în Matlab, Ed. ANMB, 2015, Constanţa, România. 